\title{
Erratum to: Incidence of second hip fracture and compliant use of bisphosphonate
}

\author{
Y.-K. Lee • Y.-C. Ha • B.-H. Yoon • K.-H. Koo
}

Published online: 13 May 2014

(C) International Osteoporosis Foundation and National Osteoporosis Foundation 2014

\section{Erratum to: Osteoporos Int}

DOI 10.1007/s00198-012-2250-0

In the fourth paragraph of the Discussion section of this article, the second sentence states: "One study reported a protective effect of bisphosphonate for the prevention of a second hip fracture."

This is incorrect. The sentence should read as follows, substituting the word "adverse" for "protective": "One study reported an adverse effect of bisphosphonate for the prevention of a second hip fracture."

The authors apologize for this error.

The online version of the original article can be found at http://dx.doi.org/ 10.1007/s00198-012-2250-0.

Y.-K. Lee • B.-H. Yoon · K.-H. Koo

Department of Orthopaedic Surgery, Seoul National University

Bundang Hospital, 166 Gumi-ro, Bundang-gu,

Seongnam 463-707, South Korea

\section{Y.-C. Ha $(\bowtie)$}

Department of Orthopaedic Surgery,

Chung-Ang University College of Medicine,

224-1 Heukseok-dong, Dongjak-gu, Seoul 156-755, South Korea

e-mail: hayongch@naver.com 